\title{
Stimulus suffix effects with speech and nonspeech sounds
}

\author{
EDWARD J. ROWE and W. GORDON ROWE
}

Memorial University of Newfoundland, St. John's, Newfoundland, Canada A IC 5S7

\begin{abstract}
The stimulus suffix effect (SSE) was examined with short sequences of words and meaningful nonspeech sounds. In agreement with previous findings, the SSE for word sequences was obtained with a speech, but not a nonspeech, suffix. The reverse was true for sounds. The results contribute further evidence for a functional distinction between speech and nonspeech processing mechanisms in auditory memory.
\end{abstract}

Several recent experiments suggest that speech and nonspeech auditory stimuli are handled by separate processing mechanisms. Deutsch (1970) compared performance on a same-different judgment task for pairs of tones as a function of whether other tones or spoken numbers were interpolated during the 5 -sec interval separating the two comparison tones. She found that interpolated tones impaired performance, while interpolated numbers had no effect. Rowe, Philipchalk, and Cake (1974) examined retention of triads of meaningful sounds vs. words in the Brown-Peterson paradigm under either verbal (shadowing poetry) or nonverbal (shadowing music) distractor activity. In that experiment, the recall difference between sounds and words depended critically on the type of distractor task, in that words were recalled better following music distraction while sounds were recalled better following poetry distraction, again suggesting different processes for retention of the two types of items. The distinction is further supported by the demonstration of hemispheric differences in the identification of speech and nonspeech sounds (e.g., King \& Kimura, 1972).

When subjects are asked to recall, in order, a short sequence of auditory items (e.g., digits) which is followed by a redundant suffix (e.g., zero), performance on the last few positions in the sequence is impaired relative to a no-suffix condition. According to the explanation of this stimulus suffix effect (SSE) given by Crowder and Morton (1969), retention of the recency items is normally mediated, at least partly, by a precategorical acoustic store (PAS), which keeps them available in a relatively unprocessed form for a second or two following presentation. In a series of experiments summarized by Crowder (1972), it has been shown that the SSE (a) occurs with an auditory but not a visual suffix (Morton \& Holloway, 1970), (b) occurs with a speech sound but not with a nonspeech sound (Crowder,

This research was funded by Grant $\mathbf{A 8 5 8 0}$ from the National Research Council of Canada to Edward J. Rowe. Experiment I is based on an undergraduate thesis project carried out by $W$. Gordon Rowe.
1971; Morton, Crowder, \& Prussin, 1971), (c) is unaffected by the meaningfulness of the suffix or its semantic relation to the sequence items (Crowder \& Raeburn, 1970; Morton et al., 1971), but (d) is maximized by physical similarities between the suffix and the list (Morton et al., 1971). These results all support the status of PAS as a literal, auditory-based coding system for speech.

The study reported here investigated the SSE with sequences of meaningful nonspeech sounds. It was conceived simply as an extension of the finding of Crowder (1971) and Morton et al. (1971) that, for speech items, the SSE is restricted to the use of a speech stimulus as the suffix. If sounds and words are processed via separate systems, then, with sound sequences, the SSE should obtain only when the suffix is a nonspeech item. There is already some indication that this might be the case. Leshowitz and Hanzi (1974) have shown a reduction in the recency effect obtained in immediate recognition of short sequences of tones when an additional tone followed the final item. However, the question of whether or not the effect can be demonstrated in the typical serial recall paradigm, and, if so, whether it occurs only with a nonspeech suffix, remains unanswered. In Experiment I, immediate ordered recall of short sequences of sounds and words was compared following presentation of either a speech or nonspeech suffix.

\section{EXPERIMENT I}

\footnotetext{
Method

Subjects. The subjects were 32 undergraduates of Memorial University who participated in the experiment for a payment of $\$ 2.00$.

Materials. The nonspeech items were common environmental sounds, and the speech items were their verbal labels. Each 7-item sound sequence was a random arrangement of shortened segments of four easily recognizable items drawn from a set of 24 used by Rowe et al. (1974). The four sounds and their presentation times were: whip $(.4 \mathrm{sec})$, siren $(.7 \mathrm{sec})$, bell $(.7 \mathrm{sec})$ and telephone $(.6 \mathrm{sec})$. The sound segments were chosen so that
} 


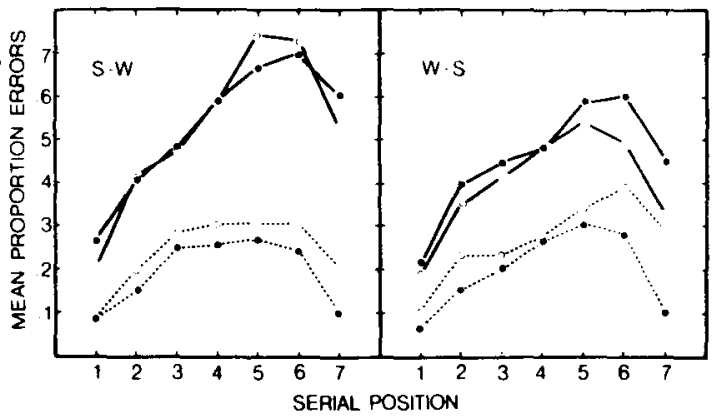

Figure 1. Serial position errors for sounds (solid lines) and words (broken lines) in Experiment I. Speech suffix conditions are represented by open circles, and nonspeech suffix conditions are closed circles. The left panel depicts the results obtained when the sounds preceded the words, and the right panel the reverse order of testing.

they represented a readily identifiable segment of each sound (e.g., one telephone ring). Sixteen different sequences were constructed by splicing together individual copies of the sounds. The sequences averaged $7 \mathrm{sec}$ in length. The individual items were separated by a silent interval of $.4 \mathrm{sec}$ and thus, on the average, occurred at a $1-\mathrm{sec}$ rate. Each sequence contained a repetition of three of the items and a single presentation of the remaining item. Repetitions were always separated by one or two items and were equally distributed throughout the seven serial positions. Across sequences, each item occurred in each serial position an equal number of times and was used as a repetition equally often.

The 16 sequences were divided into four blocks (A B C D) of four sequences each and duplicated to give a total of 32 , in which the blocks occurred in the order A B C D B C A D. This arrangement insured that at least eight other sequences came between a given sequence and its repetition. One of the two types of stimulus suffix was added to each of the four sequences in a block. The nonspeech (N) suffix was the sound of a car horn $(.7 \mathrm{sec})$ while the speech (S) suffix was the word go $(.6 \mathrm{sec})$ recorded in a male voice. The interval between the end of the seventh item and the suffix was the same as that between the other items in the sequence. Across blocks, half of the subjects received the two suffix conditions in the order NSSNSNNS while the other half received the order SNNSNSSN. Thus, each block of sequences was tested equally often in the speech and nonspeech suffix conditions. The word sequences were recorded at a $1-\sec$ rate in a male voice at the same volume as the sounds. The order of items within and between sequenœes as well as the type and arrangement of the suffixes exactly paralleled that for the sounds.

Procedure. The subjects were tested in small groups of 4-6 in a partially sound deadened room with the sequences presented through a loudspeaker. All subjects received both the sound and word sets, with half receiving the sounds first and half the words first. A short familiarization session, consisting of two individual presentations of each of the stimulus items and suffixes, preceded presentation of both sound and word sets. Each presentation of the familiarization items was separated by $5 \mathrm{sec}$ of silence. The experimenter insured that each subject could identify and, in the case of the sounds, label each item correctly. The experimental sequences were then presented. Each sequence was followed by a $12-\sec$ silent interval on the tape during which the subjects attempted to write down the first letter of the name of each item in the correct serial order on a prepared answer sheet. They were instructed to begin their recall at the beginning of the list and leave a blank for those items they could not remember. A "stop writing" signal, recorded on the tape, marked the end of the recall period, with a further $2 \mathrm{sec}$ of silence occurring between the "stop writing" signal and presentation of the next sequence. The entire session lasted about $45 \mathrm{~min}$.

\section{Results}

Items were considered as correctly recalled only if they were recalled in their input serial position. The first eight sequences of both sound and word sets were designated as practice and were not scored. The number of errors of recall made on the remaining 48 sequences were analyzed by a four-way analysis of variance with sequence type (sounds and words), suffix type (speech and nonspeech), serial position (1-7) and presentation order of sequences (sounds-words and words-sounds) as factors. All reported $F$ ratios were significant at the .05 level or better. Because there were significant interactions involving presentation order (see below), the data are plotted separately for the two levels of this factor in Figure 1.

As illustrated, more errors occurred for the sound than for the word sequences $\left[F(1 / 30)=151, S_{x}=.94\right]$. This confirms the results of several previous experiments which have compared ordered recall of sounds and words and have found that sounds are inferior (Philipchalk \& Rowe, 1971; Rowe, 1974). There were several interactions involving sequence type. An interaction with serial position $[F(6 / 180)=9.91]$ reflects a smaller difference between sound and word sequences for items near the beginning of the list. This effect, and a further interaction of List Type by Presentation Order $[F(1 / 30)=6.52]$, were both qualified by the three-way interaction of List Type by Serial Position by Presentation Order $[F(6 / 180)=3.30]$, showing that the sound-word differences across serial positions were more pronounced when the sound sequences occurred first. Practice in using the names of the sounds reduced the number of errors in recall, especially in the recency portion of the serial position curve, suggesting that retention of serial order for sounds is enhanced if the availability of their verbal labels is increased. The interaction with presentation order found here has not, however, been obtained in previous research which parallels the present experiment except for the presence of the stimulus suffix (Rowe, 1974), so its generality is somewhat questionable. Neither the main effect of presentation order $\left[S_{X}=1.84\right]$ nor suffix type $\left[\mathrm{S}_{\mathrm{x}}=.38\right]$ was significant

Sequence type interacted with suffix type $[F(1 / 30)=12.1]$ such that overall errors were higher when the type of suffix matched the type of sequence. As Figure 1 shows, and as the three-way interaction of Sequence Type by Suffix Type by Serial Position $[F(6 / 180)=3.63]$ confirmed, the effect of the suffix was more pronounced for items located at the end of a sequence. The SSE was tested for statistical significance 
by a series of correlated $t$ tests for the final two serial positions of each of the four pairs of curves in Figure 1. The curves differed significantly from each other $(p<.05)$ at Serial Position 7 for all four comparisons. At Position 6, the difference was significant only for the word-sound presentation order. Finally, the main effect of serial position was of course significant $\left[F(6 / 180)=56.7, S_{x}=.19\right]$.

The results obtained with the word sequences simply replicate previous findings that the SSE occurs only with a speech suffix. The data on recall of the sounds, however, extend these findings by demonstrating that a comparable SSE occurs for sequences of nonspeech as well as speech items. The implications of this result will be discussed below. First, because the sounds results are novel, a replication of that part of Experiment $I$ is presented as Experiment II. Experiment II was also intended to extend the limits of the result somewhat by using sequences of a different length from those of Experiment I.

\section{EXPERIMENT II}

\section{Method}

A series of 32 five-item sequences of the same four sounds used in Experiment I was constructed, following the same procedures as in that experiment. Each sequence contained each of the four sounds and a nonadjacent repetition of one of them with the location of the repetitions and the individual items balanced across serial positions. The two suffixes were presented in blocks, counterbalanced across subjects, as in Experiment I. The procedural details of the first experiment, such as familiarization trials, presentation parameters, and recall instructions, were followed here. The subjects were 32 paid undergraduate volunteers.

\section{Results}

The serial position error curves for the two suffix conditions are shown in Figure 2. Obviously, the nonspeech suffix again selectively impaired recall from Positions 4 and 5 . This was confirmed by an analysis of variance of the raw data, which showed a significant interaction of Suffix Condition by Serial Position $[F(4 / 124)=10.4]$. Serial position was significant as a main effect $[F(4 / 124)=55.3]$, but the overall difference between the two suffix conditions was not $\left[\mathrm{S}_{\mathrm{X}}=.51\right]$. However, the two curves differed reliably at Positions 4 and 5 ( $p<.01$, as assessed by t tests).

\section{DISCUSSION}

This study has shown that, in the auditory modality, the SSE occurs when the memory items and the suffix are both presented in either a speech or nonspeech format but not when the mode of presentation is mixed. The results have implications for the way in which sounds are stored in immediate memory. Terminal items in the sound sequences were apparently encoded nonverbally as sounds and not simply on the basis of their names. If these items were recoded as words, a speech suffix would be expected to affect their recall as it did with the word sequences. Clearly, such was not the case. Storage of terminal list items was modality specific, supporting previous evidence for independent verbal and nonverbal processing systems in the auditory modality. This does not mean that sounds are always, or even typically, stored solely as nonverbal images. Rowe et al. (1974) suggested, on the basis of selective interference effects in short-term retention, that sounds are stored in a nonverbal format. However, the overall pattern of results from that experiment, which required recall of only three items at a time. presented at an average rate of about $3 \mathrm{sec}$ each, suggested that the sounds were named as well. Furthermore, Bower and Holyoak (1973) have shown that verbal coding enhances retention of ambiguous sounds on a long-term recognition test. Obviously, the way in which sounds are encoded varies with the constraints of a given experiment. What the selective interference studies show is that a nonverbal coding option is a vailable.

That the sounds in terminal list positions were stored nonverbally in the present experiments is perhaps surprising, since Rowe (1974) has shown that these items can be named at presentation under conditions like those used here. Furthermore, the recall procedure itself requires that the names of the sounds be used. If they are not named at presentation, they must be decoded into a verbal format at recall. Herein may lie at least part of the reason for the overall inferiority of sounds in the ordered recall task. As noted before, the difference between sound and word sequences in Experiment I was reduced following practice on the words (see Figure 1). More extended practice would perhaps eliminate the difference altogether. It is known that prolonged experience with sequences of artificial sounds causes a marked improvement in retention of their serial order (Neisser \& Hirst, 1974; Warren, 1974).

If one accepts the existence of the SSE as prima facie evidence for a representational (precategorical) memory system, then the data reported here support such a

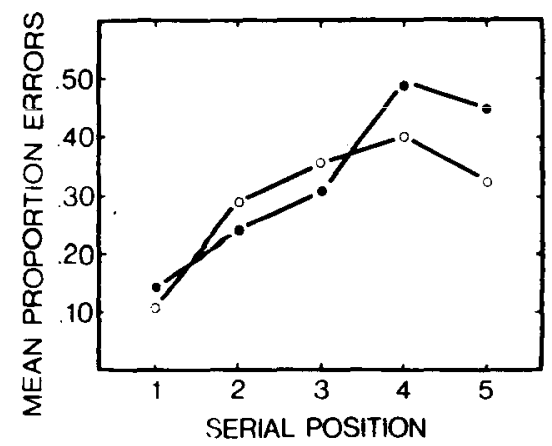

Figure 2. Serial position error curves for sound sequences with speech (open circles) and nonspeech (closed circles) suffix conditions. 
system for meaningful nonspeech sounds. However, the inference is not that simple. In Crowder's work, it is not merely the existence of the SSE per se, but the way it interacts with other variables (e.g., the relationship of the suffix to the sequence items, delay of the suffix) which provides the basis for inferring PAS. In addition, results from other sources, such as the modality effect in immediate recall and partial report studies, provide convergent support for the inference. The present data establish that the SSE occurs with nonspeech sounds and is specific to a nonspeech suffix. This may provide an initial step towards establishing the reality of a sensory nonspeech store, but does not demand it.

There have been recent demonstrations of the SSE in modalities other than auditory. Watkins and Watkins (1974) obtained an SSE in the tactile modality, and Kahneman (1973, pp.133-134) reports an effect using visual items. These findings, along with the results reported here suggest that the SSE is a more general phenomenon than originally supposed. Such being the case, it might prove profitable to seek some more general explanation of the effect than to postulate a different sensory store for every different SSE. Consider, for example, Kahneman's (1973) explanation in terms of selective attention. By this view, the stimulus sequence is processed in a postcategorical short-term store, to which the suffix can be denied access by a selective attention mechanism if it can be differentiated from the sequence items. If not, it also enters the store and interferes with retention. Since the similarity relations between the suffix and the memory items which are important in producing the SSE are those to which selective attention is often insensitive, the model can account for most of the current evidence, including that presented here.

\section{REFERENCES}

Bower, G. H., \& Holyoak, K. Encoding and recognition memory for naturalistic sounds. Journal of Experimental Psychology, $1973,101,360-366$.

Crowder, R. G. Waiting for the stimulus suffix: Delay, decay thythms, and readout in immediate memory. Quarterly Journal of Experimental Psy chology, 1971, 23, 324-340.

Crowder, R. G. Visual and auditory memory. In J. F. Kavanagh and I. G. Mattingly (Eds.), Language by eye and ear: The relation between speech and learning to read. Cambridge: M.I.T. Press, 1972.

Crowder, R. G., \& Morton, J. Precategorical acoustic storage. Perception \& Psy chophysics, 1969, 5, 365-373.

Crowder, R. G., \& Raeburn, V.P. The stimulus suffix effect with reversed speech. Journal of Verbal Learning and Verbal Behavior, 1970, 9, 342-345.

Deutsch, D. Tones and numbers: Specificity of interference in immediate memory. Science, 1970, 168. 1604-1605.

Kahneman, D. Attention and effort. Englewood Cliffs, N.J.: Prentice-Hall, 1973.

King. F. L., \& Kimura, D. Leftear superiority in dichotic perception of vocal nonverbal sounds. Canadian Journal of Psychology, 1972, 26, 111-116.

Leshowitz, B., \& Hanzi, R. Serial position effects for tonal stimuli. Memory \& Cognition, 1974, 2, 112-116.

Morton, J., Crowder, R. G., \& Prussin, H. A. Experiments with the stimulus suffix effect. Joumal of Experimental Psychology, 1971, 91, 169-190.

Morton, J., \& Holloway, C. M. Absence of a cross-model "suffix effect" in short-term memory. Quarterly Joumal of Experimental Psy chology, 1970, 22, 167-176.

Neisser, U., \& Hirst, W. Effect of practice on the identification of auditory sequences. Perception \& Psychophy aics, 1974, 15, 391-398.

Philipchalk, R., \& Rowe, E. J. Sequential and nonsequential memory for verbal and nonverbal auditory stimuli. Journal of Experimental Psy chology, 1971, 91, 341-343.

Rowe, E. J. Ordered recall of sounds and words in short-term memory. Bulletin of the Psychonomic Society, 1974, 4, 559-561.

Rowe, E. J., Philipchalk, R. P., \& Cake, L. Short-term memory for sounds and words. Journal of Experimental Psy chology, 1974, 102, 1140-1142.

Watkins, M. J., \& Watkins, O. C. A tactile suffix effect. Memory \& Cognition, 1974, 2, 176-180.

Warren, R. M. Auditory temporal discrimination by trained listeners. Cognitive Psy chology, 1974, 6, 237-256.

(Received for publication October 18, 1974; revision received December $2,1974$. 